\title{
Role of Paraventricular Nucleus Glutamate Signaling in Regulation of HPA Axis Stress Responses
}

\author{
Nathan K. EVANSON ${ }^{1}$ and James P. HERMAN ${ }^{2, *}$ \\ ${ }^{1}$ Cincinnati Children's Hospital Medical Center, Department of Pediatrics, \\ Pediatric Rehabilitation Division, 3333 Burnet Ave, MLC 4009, Cincinnati, OH 45229, U.S.A. \\ ${ }^{2}$ Department of Psychiatry, University of Cincinnati, \\ 2170 E. Galbraith Road, Cincinnati, OH 45237, U.S.A.
}

Received July 25, 2015; final version accepted July 31, 2015

\begin{abstract}
The hypothalamus-pituitary-adrenal (HPA) axis is the main neuroendocrine arm of the stress response, activation of which leads to the production of glucocorticoid hormones. Glucocorticoids are steroid hormones that are secreted from the adrenal cortex, and have a variety of effects on the body, including modulation of the immune system, suppression of reproductive hormones, maintenance of blood glucose levels, and maintenance of blood pressure. Glutamate plays an important role in coordination of HPA axis output. There is strong evidence that glutamate drives HPA axis stress responses through excitatory signaling via ionotropic glutamate receptor signaling. However, glutamate signaling via kainate receptors and group I metabotropic receptors inhibit HPA drive, probably via presynaptic inhibitory mechanisms. Notably, kainate receptors are also localized in the median eminence, and appear to play an excitatory role in control of CRH release at the nerve terminals. Finally, glutamate innervation of the PVN undergoes neuroplastic changes under conditions of chronic stress, and may be involved in sensitization of HPA axis responses. Altogether, the data suggest that glutamate plays a complex role in excitation of CRH neurons, acting at multiple levels to both drive HPA axis responses and limit over-activation.
\end{abstract}

KEYWORDS: glutamate, HPA axis, stress, chronic stress, plasticity

\section{Introduction}

The mammalian body has evolved a number of systems that are specialized to maintain homeostasis in the face of various challenges. Such systems include the hemostasis system for responding to hemorrhage, the insulin/glucagon system for responding to alterations in blood glucose levels, brown adipose tissue/shivering for responding to decreased body temperature, etc. In addition to these specialized homeostatic mechanisms, however, there are also generalized homeostatic systems that are activated regardless of the specific threat.

The existence of a generalized response to varied homeostatic challenges was first described by the Canadian endocrinologist, Hans Selye. Selye described a constellation of responses common to a variety of challenges, such as heat, cold, toxins, and surgery, and called the response to these stimuli the "general adaptation syndrome" [1]. Animals that were exposed to noxious stimuli at first adapted to the challenge, but eventually experienced physiological responses including weight loss, immune suppression, and gastrointestinal ulcers. The responses that Selye noted were common to a wide variety of seemingly unrelated noxious stimuli. The responses involved in mediating the general adaptation syndrome eventually became known as "stress" [2]. Stress responses are mediated by physiological systems, such as the adrenal medullary system, the sympathetic nervous system, and the hypothalamus-pituitary-adrenal (HPA) axis.

The HPA axis is a neuroendocrine system, comprised of the paraventricular nucleus of the hypothalamus (PVN), the anterior lobe of the pituitary gland, and the adrenal cortex. In response to stress, the PVN integrates signals from multiple levels of the brain and brainstem to promote corticotropin releasing hormone (CRH) and vasopressin (AVP) secretion into the hypophyseal portal vasculature. These hormones can then access the anterior pituitary and stimulate the synthesis and release of adrenocorticotropin (ACTH). ACTH is released into the general circulation, and acts on the adrenal cortex to induce the synthesis of glucocorticoid hormones (mainly cortisol in humans, corticosterone in rodents).

Glucocorticoid hormones that are released in response to activation of the HPA axis are involved in a number of processes that help an organism to maintain homeostasis. For example, glucocorticoids act to elevate blood glucose levels, to inhibit reproductive activities of an organism, to regulate the immune system, and to maintain or regulate blood pressure (such as in preventing shock). These activities are thought to help the animal to survive acute challenges 
to homeostasis, and to recover following the survival of such an acute challenge [3]. Glucocorticoids also serve to regulate the HPA axis response to subsequent stressors, through negative feedback [4].

\section{Excitatory regulation of the HPA axis}

Since the HPA axis is involved in the response of an organism to stress, it is clear that activity of the HPA axis needs to be regulated in a rapid manner. Although the HPA axis is typically activated more slowly than other parts of the stress response, such as the sympathetic nervous system and the adrenal medullary catecholamine system [3], the HPA axis is still activated relatively quickly in response to stress. ACTH secretion is detectably increased within 5 minutes after the onset of restraint stress [5], while corticosterone secretion is detectably increased within less than 15 minutes after the onset of stress [6].

A major player in activation of the HPA axis response to a challenge is the neurotransmitter glutamate. Glutamate is an amino acid, and is the major excitatory neurotransmitter in the central nervous system [7,8]. It is released from presynaptic nerve terminals, and removed from the synapse largely by astrocytes [9]. Glutamate signals presynaptically and post-synaptically, through a family of receptors that includes ionotropic and metabotropic members.

The ionotropic glutamate receptors act as glutamate-gated ion channels, and are divided into three general families, based on homology and pharmacological properties of the receptor proteins. These families are the N-methyl-Daspartate (NMDA) receptors, the $\alpha$-amino-3-hydroxy-5-methyl-4-isoxazolepropionic acid (AMPA) receptors, and the kainate receptors [10]. Ionotropic receptors, particularly the AMPA receptors, mediate most of the fast excitatory signaling in the central nervous system [8,11]. NMDA [12] and kainate receptors [13] both have roles in synaptic plasticity as well. Figure $1 \mathrm{~A}$ summarizes the ionotropic glutamate receptors.

Metabotropic receptors signal through G-proteins, and are also divided into three groups, known as Groups I, II, and III [14]. In general, group I receptors are post-synaptic and excitatory, via phospholipase C signaling. Groups II and III act as presynaptic autoreceptors, inhibiting adenylate cyclase activity and thus inhibiting presynaptic glutamate release $[14,15]$. Figure 1B summarizes the metabotropic glutamate receptors.

A

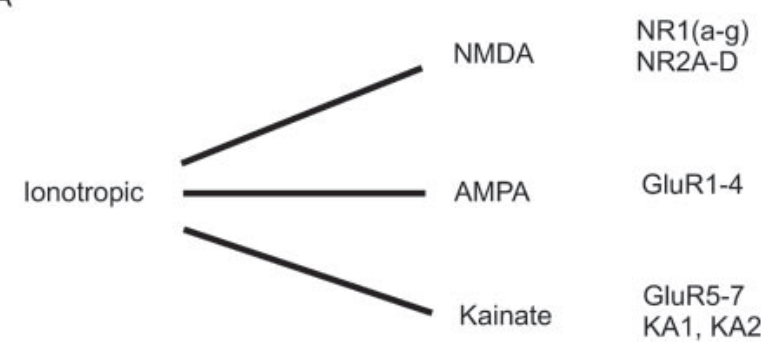

B

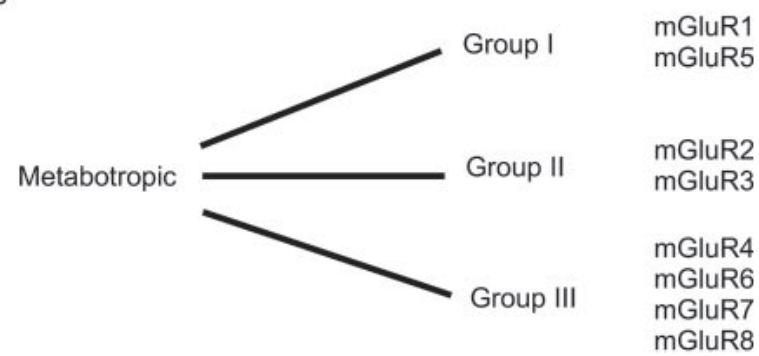

Fig. 1. Glutamate receptor families. Glutamate receptors are divided roughly into ionotropic (A) and metabotropic (B) glutamate receptors. Each of these is subdivided into three groups. The members of each group are outlined.

\section{Glutamate and acute regulation of the HPA axis}

Since glutamate is the major excitatory central nervous system neurotransmitter, it is not surprising that glutamate signaling is an important regulatory influence on the HPA axis. Cells in many areas involved in activation of the HPA axis express glutamate receptors, suggesting that glutamatergic terminals innervate these areas. These regions include the PVN, hippocampus, prefrontal cortex, and the anterior pituitary gland [16-19], suggesting an anatomic basis for glutamate signaling in activation of the HPA axis. Furthermore, neurons in the PVN proper and in areas that send efferents to the PVN express glutamate transporter proteins such as vesicular glutamate transporter 1 (VGluT1), VGluT2, and VGluT3 [20-24], which define them as glutamatergic neurons. 
Using retrograde tracing in combination with VGluT1 and VGluT2 in situ hybridization, our group has determined that the major glutamate inputs to the PVN are from diencephalic and brainstem sources. Tracing studies highlight the posterior hypothalamus and ventromedial hypothalamus as primary hypothalamic glutamatergic PVN inputs, showing the highest proportion of retrogradely labeled, VGluT2 positive neurons. Anterograde tracing in conjunction with VGluT2 immunostaining confirm that the posterior hypothalamic connection sends glutamatergic fibers into the CRHcontaining region of the PVN [25]. A strong glutamatergic projection from the subparafascicular nucleus of the thalamus is also observed. Strong projections exist from several brainstem sources, including the anterior and caudal periaqueductal gray and lateral parabrachial nucleus. There is also evidence for glutamate projections from the ventrolateral medulla and nucleus of the solitary tract [26]. At least some of the latter projections co-express catecholaminergic or peptidergic (e.g., glucagon-like peptide 1) markers [27]. These expression and tracing studies suggest a functional role for glutamate in regulation of the HPA axis, which has been confirmed on both acute and chronic time scales.

Acutely, glutamate infusion into the third ventricle [28] or PVN [29] leads to increased corticosterone secretion. Direct PVN glutamate infusion increases ACTH secretion [30] and causes depletion of CRH from the median eminence (consistent with release of CRH) [29]. Acute excitatory effects of ionotropic glutamate receptor signaling are mediated by NMDA receptors [31,32] and non-NMDA receptors [33]. Indeed, direct infusion of the general ionotropic glutamate receptor antagonist kynurenic acid reduces corticosterone release in response to acute restraint, consistent with excitatory drive of the HPA axis by post-synaptic NMDA/AMPA receptors localized on PVN neurons [34].

Recent studies from our group also document a role for local kainate receptor signaling in regulation of PVN excitability. Direct infusion of the GluR5 kainate receptor antagonist LY382884 into the PVN region prior to restraint stress increases ACTH and corticosterone release and elevates PVN Fos induction, consistent with a role for GluR5 signaling in stress inhibition [35]. The inhibitory effect of GluR5 activation may be associated with either presynaptic inhibition of glutamate release or presynaptic excitation of local GABA release. Both of the above GluR5 effects have been reported in the literature [36-40].

In contrast to data obtained following direct PVN injections, infusion of LY382884 into the median eminence decreases ACTH and corticosterone release. As the median eminence is neuron-poor, these data suggest that GluR5 mediates presynaptic excitation of CRH release, likely from the terminals of PVN neurons [35]. Immunohistochemical analysis documents colocalization of GluR5 in CRH-immunoreactive terminals in the median eminence, further consistent with a direct role of PVN GluR5 in the median eminence. Prior studies confirm the presence of VGluT2 immunoreactivity in the median eminence, derived from the median preoptic nucleus, lamina terminalis, periventricular zone, supraoptic nucleus and the PVN itself [41]. The latter presents the intriguing possibility that median eminence glutamate release may serve as an autocrine and paracrine amplifier of hormone release. This possibility is consistent with the common phenomenon of co-release of neurotransmitters, particularly classical neurotransmitters with peptides [42]. Figure 2 outlines a model for GluR5 signaling in the PVN and median eminence, based on the above findings.

We have also investigated the role of PVN group I metabotropic receptors in regulation of stress responses. Prior studies indicate that metabotropic glutamate receptors may mediate both excitatory [43] and inhibitory [44, 45] effects

A

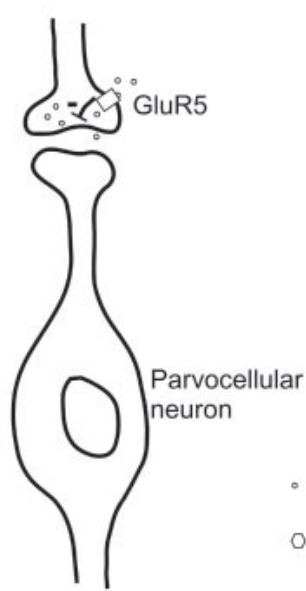

B

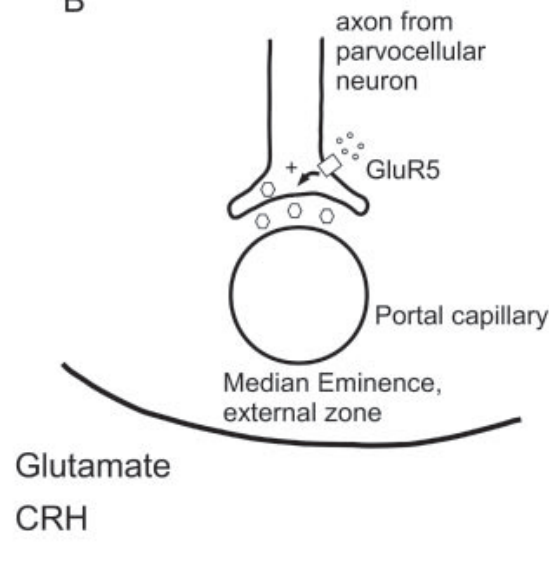

Fig. 2. Model for signaling through GluR5 at the PVN and median eminence. A) In the PVN proper, activation of GluR5 leads to an inhibitory action on the HPA axis response to stress. We have proposed that this is due to presynaptic signaling which decreases release of glutamate onto CRH containing parvocellular neurons, in an autoregulatory fashion. Decreased glutamate release leads to decreased excitation of the parvocellular neuron and thus to decreased CRH release and blunted HPA axis activity. B) At the median eminence, activation of GluR5 leads to excitation of the HPA axis response to stress. In this model, glutamate appears to act as a feed-forward signal, magnifying the release of $\mathrm{CRH}$ from parvocellular nerve terminals at the median eminence, and thus increasing HPA axis activation. 


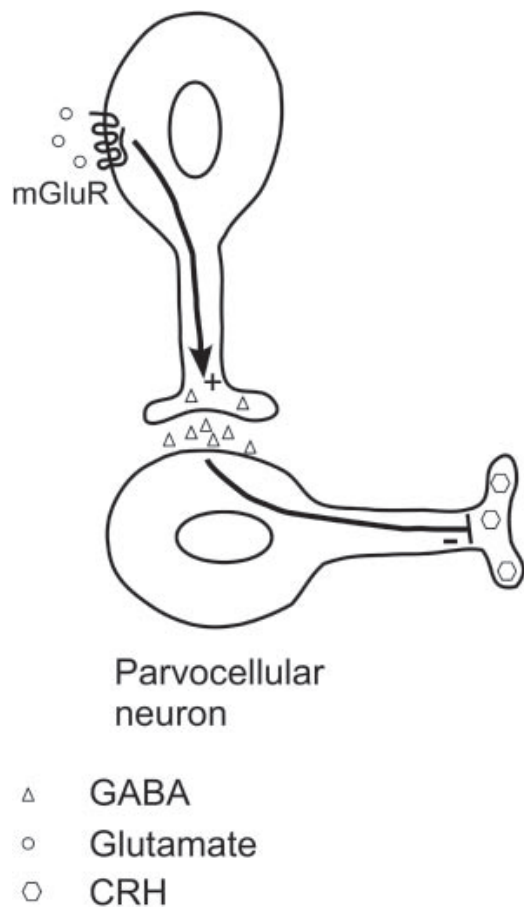

Fig. 3. Model for group I metabotropic glutamate receptor signaling at the PVN. Glutamate activates group I metabotropic glutamate receptors (mGluR), which are typically excitatory. Given that activation of these receptors leads to dampening of the HPA axis response to stress, it is plausible that this signaling leads to enhanced GABA release onto parvocellular neurons in the $\mathrm{PVN}$, thus decreasing release of $\mathrm{CRH}$ and decreasing the HPA axis response.

on HPA axis activity, on an acute time scale. Our studies indicate that intra-PVN injection of an mGluR group I agonist attenuates HPA axis stress responses, whereas receptor blockade potentiates ACTH release [46]. These data are consistent with a role for group I mGluRs in presynaptic stress inhibition, perhaps via excitation of presynaptic GABA release. Figure 3 outlines a model for group I mGluR signaling in the PVN based on these findings.

Collectively, the data suggest that while glutamate is involved in HPA axis excitation, the contribution of individual receptor populations is complex, with our studies suggesting that presynaptic kainate or group I metabotropic receptors may serve a feedback function to 'buffer' PVN excitation driven by post-synaptic glutamate receptors on PVN neurons.

\section{Glutamate and Glucocorticoid Negative Feedback}

Like most homeostatic mechanisms, the HPA axis response to activation is regulated in part by negative feedback inhibition [4]. Glucocorticoids are known to inhibit the HPA axis via local actions in the PVN. Glucocorticoids rapidly inhibit CRH release from hypothalamic slices [47,48] and synaptosomes [49]. Treatment with dexamethasone or corticosterone, but not cholesterol or isopregnanolone rapidly decreases the frequency of excitatory (glutamatergic) post synaptic currents in CRH-containing hypothalamic cells [50]. The glutamatergic effect suggests a rapid inhibitory action of glucocorticoids on CRH release, although CRH was not measured in this study. The rapid inhibitory action of glucocorticoids on parvocellular PVN neurons was mimicked by dexamethasone-bovine serum albumin (BSA) and corticosterone-BSA conjugates, which do not cross the cell membrane, indicating that non-genomic feedback occurs at the level of the cell membrane. Further studies from our group indicate that PVN fast feedback also occurs in vivo, as local PVN injection of dexamethasone $5 \mathrm{~min}$ prior to acute stress significantly blunts ACTH and corticosterone responses [51]. Suppression of HPA activation also occurred following local dex:BSA injections, indicating that inhibition is mediated at the cell membrane in vivo as well. Figure 4 outlines these findings.

More recent studies indicate that the rapid effects of glucocorticoids on PVN neurons are mediated via the canonical glucocorticoid receptor (GR). The GR is sensitive to stress levels of glucocorticoids and is generally thought to exert physiological actions via direct or indirect modulation of gene transcription in the cell nucleus. Recently, light microscopic and electron microscopic studies have localized the GR in close proximity to the cell membrane [52, 53], a location consistent with the capacity for membrane signal. The importance of GR in fast feedback was confirmed using PVN-directed knockout mice. Deletion of GR in the PVN using either a simpleminded 1 (PVN and SON-directed transcription factor, Sim-1) or $c r h$ promoter blocked fast glucocorticoid feedback inhibition of parvocellular neurons [54]. Moreover, Sim1-mediated deletion of GR enhanced peak ACTH and corticosterone responses to stress, suggesting a role for GR in rapid feedback inhibition in vivo as well [55].

The mechanism underlying glucocorticoid fast feedback appears to involve mobilization of post-synaptic 


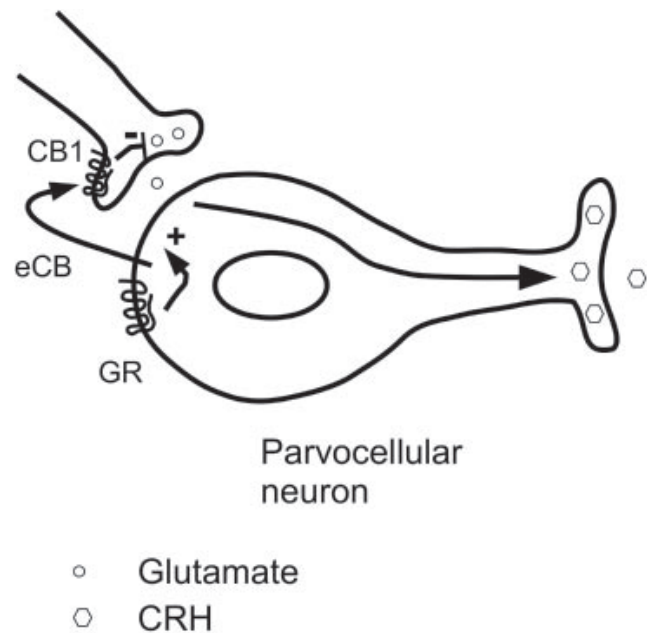

Fig. 4. Model of endocannabinoid synaptic signaling at the PVN. Glucocorticoids (GCs) act on a putative G-protein coupled receptor, which is likely a form of GR, by which they induce production of endocannabinoids $(\mathrm{eCB})$ in the postsynaptic neuron, through an unclear mechanism. eCB diffuse across the synapse in a retrograde manner, to act on $\mathrm{CB}_{1}$ receptors on the presynaptic terminal. This leads to decreased release of glutamate onto the postsynaptic cell. Decreased glutamatergic input onto the CRH-containing postsynaptic cell leads to decreased CRH release and therefore to decreased HPA axis activity.

endocannabinoid (EC) signaling, which results in presynaptic inhibition of glutamate release via retrograde signaling. Exogenous application of ECs mimics the inhibitory effects of glucocorticoids on PVN excitability, and glucocorticoid fast feedback effects can be blocked by administration of a type 1 cannabinoid receptor antagonist (AM251) [50]. Similarly, local co-application of AM251 with dexamethasone blocks inhibition of HPA stress responses in vivo [51]. Importantly, acute restraint increases 2-diacyl glycerol synthesis in the PVN region, consistent with stress-induced mobilization of ECs [51].

Prior studies indicate that metabotropic glutamate receptor signaling regulates EC release, leading to inhibition of presynaptic glutamate release, such as is the case in the hippocampus [56] or cerebellum [57]. Studies in our group indicate that co-application of a group I metabotropic antagonist attenuates dexamethasone-induced inhibition of the HPA axis stress response, consistent with involvement of metabotropic glutamate signaling in regulation of fast feedback. However, local co-administration of AM251 does not attenuate inhibition of the HPA axis by a group I mGluR agonist, suggesting that metabotropic receptor mediated inhibition of the HPA axis is functionally distinct from endocannabinoid mediated fast feedback inhibition [46]. Thus, presynaptic inhibition of the HPA axis by mGluR signaling likely acts by a mechanism distinct from that of ECs.

\section{Glutamate and Chronic Stress}

Prior studies suggest a prominent role for glutamate signaling in chronic stress-induced drive of the HPA axis. Chronic treatment with an NMDA antagonist increases the corticosterone response in mice [58], while chronic concurrent inhibition of NMDA and AMPA receptors leads to decreased HPA axis response to immobilization stress [59]. Chronic stress exposure also leads to decreased NMDA receptor 2B expression in the PVN, consistent with increased excitability [60]. Consistent with increased HPA axis excitation, chronic stress leads to elevated baseline corticosterone and ACTH secretion, along with elevated CRH expression in the PVN [61].

Recent studies from our group have noted marked plasticity in glutamatergic innervation of PVN CRH neurons following imposition of chronic variable stress (CVS). Our data indicate that chronic stress results in a substantial increase in VGluT2 innervation of the parvocellular PVN of males [61-63]. The increase in innervation is also observed at the level of individual CRH neurons, as there are marked increases in the number of VGluT2 terminal appositions onto CRH-immunoreactive somata and dendrites [63]. Notably, PVN CRH and vasopressin expression are enhanced in CVS-exposed (male) rats, consistent with enhanced biosynthesis of ACTH secretagogues. In addition, CVS enhances HPA axis responses to novel stressors, consistent with increased HPA axis excitability. Taken together, these data suggest that enhanced glutamatergic innervation of the PVN may be connected with increased drive of the HPA axis by chronic stress, presumably mediated by neuroplastic events affecting PVN afferent input.

Surprisingly, the effects of chronic stress on PVN VGluT2 innervation are quite different in females. In contrast to males, the overall density of synaptophysin staining in the PVN is significantly decreased in females [62], suggesting reduced innervation of hypophysiotrophic PVN neurons. While the phenotype underlying the synaptic reduction remains to be determined, the data suggest fundamentally different neuroplastic responses to stress in males and females. Interestingly, deletion of GR in PVN neurons (Sim1-Cre, GRflox mice) does not affect the time-course of HPA axis stress response in females [55], suggesting that feedback mechanisms also differ in males vs. females. 
Collectively, these data indicate that there are fundamental sex differences in PVN stress processing. Understanding the nature of these differences may lend insight into why females are more susceptible to stress-related diseases.

\section{Conclusion}

Overall, data to date suggest a complex role for glutamate in HPA axis regulation. At the post-synaptic level, glutamate drives acute HPA axis stress responses, likely via classical actions of ionotropic glutamate receptors. At the presynaptic level, glutamate can inhibit CRH neurons via both ionotropic (GluR5) and metabotropic (group $1 \mathrm{mGluR}$ ) mechanisms, with group 1 metabotropic receptors playing a role in mediating rapid glucocorticoid negative feedback. There is also evidence for presynaptic glutamate drive at the level of the median eminence, mediated by GluR5 at CRH terminals. Chronic stress causes enhanced glutamate input into the PVN, and decreases expression of NMDA 2B receptors in the medial parvocellular PVN, which is predicted to produce a more 'active' NMDA receptor complex. The latter findings suggest a role in the enhancement of HPA axis reactivity seen under conditions of chronic stress.

The diversity of glutamate action in the PVN is receptor-dependent. Given the involvement of stress in a wide variety of disease states, use of pharmacological treatments that target specific actions of glutamate at the PVN may be a viable approach to limit damaging aspects of HPA axis over-activation.

\section{Acknowledgements}

This work was funded by MH069725 (JPH) and NS007453, DK059803, and HD001097 (NKE).

Disclosures: This work is based on a dissertation from the University of Cincinnati, which is deposited (but not traditionally published) in the public archives of the University of Cincinnati Library system.

\section{REFERENCES}

[1] Selye H (1936) A syndrome produced by diverse nocuous agents. Nature 138:32.

[2] Selye H (1956) What is stress? Metabolism 5:525-530.

[3] Sapolsky RM, Romero LM, Munck AU (2000) How do glucocorticoids influence stress responses? Integrating permissive, suppressive, stimulatory, and preparative actions. Endocr Rev 21:55-89.

[4] Keller-Wood ME, Dallman MF (1984) Corticosteroid inhibition of ACTH secretion. Endocr Rev 5:1-24.

[5] Vahl TP, Ulrich-Lai YM, Ostrander MM, Dolgas CM, Elfers EE, Seeley RJ, D’Alessio DA, Herman JP (2005) Comparative analysis of ACTH and corticosterone sampling methods in rats. Am J Physiol 289:E823-E828.

[6] Tauchi M, Zhang R, D’Alessio DA, Seeley RJ, Herman JP (2008) Role of central glucagon-like peptide-1 in hypothalamopituitary-adrenocortical facilitation following chronic stress. Exp Neurol 210:458-466.

[7] Brann DW (1995) Glutamate: a major excitatory transmitter in neuroendocrine regulation. Neuroendocrinology 61:213-225.

[8] Ozawa S, Kamiya H, Tsuzuki K (1998) Glutamate receptors in the mammalian central nervous system. Prog Neurobiol 54:581-618.

[9] Hertz L (1979) Functional interactions between neurons and astrocytes I. Turnover and metabolism of putative amino acid transmitters. Prog Neurobiol 13:277-323.

[10] Mayer ML, Armstrong N (2004) Structure and function of glutamate receptor ion channels. Annu Rev Physiol 66:161-181.

[11] Lees GJ (2000) Pharmacology of AMPA/kainate receptor ligands and their therapeutic potential in neurological and psychiatric disorders. Drugs 59:33-78.

[12] Mori H, Mishina M (1995) Structure and function of the NMDA receptor channel. Neuropharmacology 34:1219-1237.

[13] Huettner JE (2001) Kainate receptors: knocking out plasticity. Trends Neurosci 24:365-366.

[14] Pin JP, Duvoisin R (1995) The metabotropic glutamate receptors: structure and functions. Neuropharmacology 34:1-26.

[15] Benarroch EE (2008) Metabotropic glutamate receptors: synaptic modulators and therapeutic targets for neurologic disease. Neurology 70:964-968.

[16] Mahesh VB, Zamorano P, De Sevilla L, Lewis D, Brann DW. (1999) Characterization of ionotropic glutamate receptors in rat hypothalamus, pituitary and immortalized gonadotropin-releasing hormone (GnRH) neurons (GT1-7 cells). Neuroendocrinology 69:397-407.

[17] Petralia RS, Wang YX, Wenthold RJ (1994) Histological and ultrastructural localization of the kainate receptor subunits, KA2 and GluR6/7, in the rat nervous system using selective antipeptide antibodies. J Comp Neurol 349:85-110.

[18] Petralia RS, Yokotani N, Wenthold RJ (1994) Light and electron microscope distribution of the NMDA receptor subunit NMDAR1 in the rat nervous system using a selective anti-peptide antibody. J Neurosci 14:667-696.

[19] Petralia RS, Wenthold RJ (1992) Light and electron immunocytochemical localization of AMPA-selective glutamate receptors in the rat brain. J Comp Neurol 318:329-354.

[20] Poulin JF, Castonguay-Lebel Z, Laforest S, Drolet G (2008) Enkephalin co-expression with classic neurotransmitters in the amygdaloid complex of the rat. J Comp Neurol 506:943-959.

[21] Danik M, Cassoly E, Manseau F, Sotty F, Mouginot D, Williams S (2005) Frequent coexpression of the vesicular glutamate transporter 1 and 2 genes, as well as coexpression with genes for choline acetyltransferase or glutamic acid decarboxylase in neurons of rat brain. J Neurosci Res 81:506-521.

[22] Fremeau RT, Jr, Burman J, Qureshi T, Tran CH, Proctor J, Johnson J, Zhang H, Sulzer D, Copenhagen DR, Storm-Mathisen J, Reimer RJ, Chaudhry FA, Edwards RH (2002) The identification of vesicular glutamate transporter 3 suggests novel modes of 
signaling by glutamate. Proc Natl Acad Sci USA 99:14488-14493.

[23] Kaneko T, Fujiyama F, Hioki H (2002) Immunohistochemical localization of candidates for vesicular glutamate transporters in the rat brain. J Comp Neurol 444:39-62.

[24] Ziegler DR, Cullinan WE, Herman JP (2002) Distribution of vesicular glutamate transporter mRNA in rat hypothalamus. J Comp Neurol 448:217-229.

[25] Ulrich-Lai YM, Jones KR, Ziegler DR, Cullinan WE, Herman JP (2011) Forebrain origins of glutamatergic innervation to the rat paraventricular nucleus of the hypothalamus: differential inputs to the anterior versus posterior subregions. J Comp Neurol 519:1301-1319.

[26] Ziegler DR, Edwards MR, Ulrich-Lai YM, Herman JP, Cullinan WE (2012) Brainstem origins of glutamatergic innervation of the rat hypothalamic paraventricular nucleus. J Comp Neurol 520:2369-2394.

[27] Zheng H, Stornetta RL, Agassandian K, Rinaman L (2014) Glutamatergic phenotype of glucagon-like peptide 1 neurons in the caudal nucleus of the solitary tract in rats. Brain Struct Funct 220:3011-3022.

[28] Makara GB, Stark E (1975) Effect of intraventricular glutamate on ACTH release. Neuroendocrinology 18:213-216.

[29] Feldman S, Weidenfeld J (1997) Hypothalamic mechanisms mediating glutamate effects on the hypothalamo-pituitaryadrenocortical axis. J Neural Transm 104:633-642.

[30] Darlington DN, Miyamoto M, Keil LC, Dallman MF (1989) Paraventricular stimulation with glutamate elicits bradycardia and pituitary responses. Am J Physiol 256:R112-R119.

[31] Jezova D, Tokarev D, Rusnak M (1995) Endogenous excitatory amino acids are involved in stress-induced adrenocorticotropin and catecholamine release. Neuroendocrinology 62:326-332.

[32] Pechnick RN, George R, Poland RE (1989) Characterization of the effects of the acute and repeated administration of MK-801 on the release of adrenocorticotropin, corticosterone and prolactin in the rat. Eur J Pharmacol 164:257-263.

[33] Tokarev D, Jezova D (1997) Effect of central administration of the non-NMDA receptor antagonist DNQX on ACTH and corticosterone release before and during immobilization stress. Methods Find Exp Clin Pharmacol 19:323-328.

[34] Ziegler DR, Herman JP (2000) Local integration of glutamate signaling in the hypothalamic paraventricular region: regulation of glucocorticoid stress responses. Endocrinology 141:4801-4804.

[35] Evanson NK, van Hooren DC, Herman JP (2009) GluR5-mediated glutamate signaling regulates hypothalamo-pituitaryadrenocortical stress responses at the paraventricular nucleus and median eminence. Psychoneuroendocrinology 34:1370-1379.

[36] Aroniadou-Anderjaska V, Qashu F, Braga MF (2007) Mechanisms regulating GABAergic inhibitory transmission in the basolateral amygdala: implications for epilepsy and anxiety disorders. Amino Acids 32:305-315.

[37] Braga MF, Aroniadou-Anderjaska V, Xie J, Li H (2003) Bidirectional modulation of GABA release by presynaptic glutamate receptor 5 kainate receptors in the basolateral amygdala. J Neurosci 23:442-452.

[38] Campbell SL, Mathew SS, Hablitz JJ (2007) Pre- and postsynaptic effects of kainate on layer II/III pyramidal cells in rat neocortex. Neuropharmacology 53:37-47.

[39] Wu LJ, Xu H, Ren M, Zhuo M (2007) Genetic and pharmacological studies of GluR5 modulation of inhibitory synaptic transmission in the anterior cingulate cortex of adult mice. Dev Neurobiol 67:146-157.

[40] Xu H, Wu LJ, Zhao MG, Toyoda H, Vadakkan KI, Jia Y, Pinaud R, Zhuo M (2006) Presynaptic regulation of the inhibitory transmission by GluR5-containing kainate receptors in spinal substantia gelatinosa. Mol Pain 2:29.

[41] Hrabovszky E, Deli L, Turi GF, Kallo I, Liposits Z (2007) Glutamatergic innervation of the hypothalamic median eminence and posterior pituitary of the rat. Neuroscience 144:1383-1392.

[42] Trudeau LE, Gutierrez R (2007) On cotransmission \& neurotransmitter phenotype plasticity. Mol Interv 7:138-146.

[43] Johnson MP, Kelly G, Chamberlain M (2001) Changes in rat serum corticosterone after treatment with metabotropic glutamate receptor agonists or antagonists. J Neuroendocrinol 13:670-677.

[44] Bradbury MJ, Giracello DR, Chapman DF, Holtz G, Schaffhauser H, Rao SP, Varney MA, Anderson JJ (2003) Metabotropic glutamate receptor 5 antagonist-induced stimulation of hypothalamic-pituitary-adrenal axis activity: interaction with serotonergic systems. Neuropharmacology 44:562-572.

[45] Scaccianoce S, Matrisciano F, Del Bianco P, Caricasole A, Di Giorgi Gerevini V, Cappuccio I, Melchiorri D, Battaglia G, Nicoletti F (2003) Endogenous activation of group-II metabotropic glutamate receptors inhibits the hypothalamic-pituitaryadrenocortical axis. Neuropharmacology 44:555-561.

[46] Evanson NK, Herman JP (2015) Metabotropic glutamate receptor-mediated signaling dampens the HPA axis response to restraint stress. Physiol Behav 150:2-7.

[47] Jones MT, Hillhouse EW, Burden JL (1977) Dynamics and mechanics of corticosteroid feedback at the hypothalamus and anterior pituitary gland. J Endocrinol 73:405-417.

[48] Jones MT, Hillhouse EW (1976) Structure-activity relationship and the mode of action of corticosteroid feedback on the secretion of corticotrophin-releasing factor (corticoliberin). J Steroid Biochem 7:1189-1202.

[49] Edwardson JA, Bennett GW (1974) Modulation of corticotrophin-releasing factor release from hypothalamic synaptosomes. Nature 251:425-427.

[50] Di S, Malcher-Lopes R, Halmos KC, Tasker JG (2003) Nongenomic glucocorticoid inhibition via endocannabinoid release in the hypothalamus: a fast feedback mechanism. J Neurosci 23:4850-4857.

[51] Evanson NK, Tasker JG., Hill MN, Hillard CJ, Herman JP (2010) Fast feedback inhibition of the HPA axis by glucocorticoids is mediated by endocannabinoid signaling. Endocrinology 151:4811-4819.

[52] Jafari M, Seese RR, Babayan AH, Gall CM, Lauterborn JC (2012) Glucocorticoid receptors are localized to dendritic spines and influence local actin signaling. Mol Neurobiol 46:304-315.

[53] Johnson LR, Farb C, Morrison JH, McEwen BS, LeDoux JE (2005) Localization of glucocorticoid receptors at postsynaptic membranes in the lateral amygdala. Neuroscience 136:289-299.

[54] Nahar J, Haam J, Chen C, Jiang Z, Glatzer NR, Muglia LJ, Dohanich GP, Herman JP, Tasker JG (2015) Rapid Nongenomic 
Glucocorticoid Actions in Male Mouse Hypothalamic Neuroendocrine Cells Are Dependent on the Nuclear Glucocorticoid Receptor. Endocrinology 156:2831-2842.

[55] Solomon MB, Loftspring M, de Kloet AD, Ghosal S, Jankord R, Flak JN, Wulsin AC, Krause EG, Zhang R, Rice T, McKlveen J, Myers B, Tasker JG, Herman JP (2015) Neuroendocrine Function After Hypothalamic Depletion of Glucocorticoid Receptors in Male and Female Mice. Endocrinology 156:2843-2853.

[56] Doherty J, Dingledine R (2003) Functional interactions between cannabinoid and metabotropic glutamate receptors in the central nervous system. Curr Opin Pharmacol 3:46-53.

[57] Kano M, Hashimoto K, Tabata T (2008) Type-1 metabotropic glutamate receptor in cerebellar Purkinje cells: a key molecule responsible for long-term depression, endocannabinoid signalling and synapse elimination. Philos Trans R Soc Lond B Biol Sci 363:2173-2186.

[58] Pistovcakova J, Makatsori A, Sulcova A, Jezova D (2005) Felbamate reduces hormone release and locomotor hypoactivity induced by repeated stress of social defeat in mice. Eur Neuropsychopharmacol 15:153-158.

[59] Zelena D, Makara GB, Jezova D (1999) Simultaneous blockade of two glutamate receptor subtypes (NMDA and AMPA) results in stressor-specific inhibition of prolactin and corticotropin release. Neuroendocrinology 69:316-323.

[60] Ziegler DR, Cullinan WE, Herman JP (2005) Organization and regulation of paraventricular nucleus glutamate signaling systems: N-methyl-D-aspartate receptors. J Comp Neurol 484:43-56.

[61] Herman JP, Adams D, Prewitt, C (1995) Regulatory changes in neuroendocrine stress-integrative circuitry produced by a variable stress paradigm. Neuroendocrinology 61:180-190.

[62] Carvalho-Netto EF, Myers B, Jones K, Solomon MB, Herman JP (2011) Sex differences in synaptic plasticity in stressresponsive brain regions following chronic variable stress. Physiol Behav 104:242-247.

[63] Flak JN, Ostrander MM, Tasker JG, Herman JP (2009) Chronic stress-induced neurotransmitter plasticity in the PVN. J Comp Neurol 517:156-165. 